\title{
PERCEPTION OF ADAPTATION OF A SPATIAL ENVIRONMENT FOR SUCCESSFUL MOVEMENT OF PERSONS WITH DISABILITIES
}

\section{Izeta Husić-Đuzić Ševala Tulumović ${ }^{1}$}

Faculty of Education and Rehabilitation, University of Tuzla, Bosnia and Herzegovina

\author{
Original scientific paper
}

Received: 05.7.2018

Accepted: 25.8.2018

\begin{abstract}
The aim of the paper is to show differences in the accessibility of the environment between young people with disabilities and young people without disabilities. The sample of respondents consisted of two sub-samples. The first sub-sample was composed of young people with disabilities, chronologically aged 18-35, both sexes 50 of them. The second subsample consisted of young people without disabilities, chronologically aged 18-35, both sexes 50 of them, selected by random selection method from the Tuzla Canton area. The data obtained by the research were processed using the method of parametric and nonparametric statistics. Frequencies, percentages and measures of central tendency are calculated (arithmetic mean, standard deviation). To investigate the differences between the tested variables, $p$-values were used, and variance analysis was used to test the significance of the differences. The obtained results showed that there is a statistically significant difference in the adaptability of space and the accessibility of the environment between young people with disabilities and young people without disabilities. Young people with disabilities are the worst evaluators of the accessibility of public transport and the environment, and the best evaluators of accessibility of housing.
\end{abstract}

Keywords: young people with disabilities, young people without disabilities, accessibility.

\section{INTRODUCTION}

An independent individual is one who does not depend on others or does not want to depend on others, which does not mean that others do not need or do not want them. Being a young person carries a lot of responsibility but also ambition. The desire of every young person is to be independent and successful in all aspects of life. In order to achieve this, family support is necessary, but also certain skills that will facilitate the path to success (Husić-Đuzić, 2016). Negative attitudes on the part of the environment can affect self-confidence of young people with disabilities. The independence of persons with disabilities is particularly affected by the problem of barriers and accessibility. Despite the existence of positive legal regulations on accessibility of the environment for people with disabilities, the same is not fully applied in practice or in some places it is not applied at all.

\footnotetext{
${ }^{1}$ Correspondence to:

Švala Tulumović, PhD, Faculty of Education and Rehabilitation, University of Tuzla, Bosnia and Herzegovina Univerzitetska 1, 75000 Tuzla, Bosnia and Herzegovina

Phone:+387 35-320 673

E-mail: sevala.tulumovic@untz.ba
} 
All existing institutions are still not sufficiently accessible for people with disabilities. In addition to all of the above, in our country, young people with disabilities sometimes manage to achieve their goals and are very successful in overcoming the obstacles that are on their way. For them as well as for people with disabilities, it is a lifelong learning to be able to live and master all the necessary skills for it. Accessibility means that people with disabilities have access to, on an equal basis with others, physical environment, means of transport, information and communication technologies and systems (ICTs), as well as other facilities and services. In all these areas there are still huge obstacles. In the European Union, on average, only $5 \%$ of public websites are fully compliant with Internet accessibility standards. However, many are partially accessible. Many TV broadcasters still have little titled and audio-described programs designed for people with disabilities (European Strategy for People with Disabilities 2010-2020). These measures, which include identifying and removing obstacles and barriers to accessibility, relate, inter alia, to: buildings, roads, transport and other indoor and outdoor spaces, including schools, housing, health facilities and workplaces, information, communications and other services, including electronic services and emergency services. Physical accessibility is important for people with severe mobility and physical disabilities in the selection process, as well as possible later employment. Required accessibility elements are defined in: accessibility elements for overcoming altitude differences (e.g. ramp, staircase, elevator, vertical lifting platform, sloping lifting platform), accessibility elements of independent life (e.g. bathrooms, kitchens, rooms /classrooms/ workspace, coffee shop and restaurant, telephone, text phone, fax, ATM, door handles and windows, counter, desk, orientation plan for the movement in the building etc.) elements of accessibility of public transport (e.g. stop and platform, parking place, etc.). Mandatory elements of accessibility are applied by selecting the most favourable solution in relation to the purpose and other features of the building (Matković \& Načinović, 2015). The commitment of the society is to ensure that all persons with disabilities feel less affected by the consequences of disability by providing adequate health care, rehabilitation, a safer environ- ment and raising the awareness of a community that is ready to support people with disabilities (Petition for Support of Persons with Disabilities, 2015). According to the knowledge of oneself, the person sets the expectations of himself. These expectations can be real, but they can be lower or higher than what can really be achieved in a situation (Seligman, 2007). Self-esteem in people with disabilities is defined by the assessment of their own capacities for functioning in the social environment (Omolayo, 2009). Activities of everyday life include tasks for which a person is regularly prepared or as an accessory to participate in his or her social roles and work (Trombly, 1995). Possession and use of social skills of young people with disabilities affects life and professional achievements, social relations, and family relationships (Bratovčić \& Galijasevic, 2015). They allow young people with disabilities to solve problems in relation to other people and the ability to control behaviours such as wearing anger and frustration. According to Erikson's theory (Erikson, 2008), the stage of identity formation occurs during adolescence. Due to great biological changes, more complex ways of thinking, redefining oneself within the family, developing new forms of relationships with peers, and adapting to the increasing demands of the education system, adolescents at this stage re-examine themselves and their environment. In order to achieve the basis for a standardized assessment of the functioning of persons, and their interaction with the environment, it is necessary to make a specification for each of the selected functions, activities and environmental factors when there is no damage for the observed variable, if the damage is mild, moderate, severe or complete (Strnad \& Benjak, 2010). The social model of disability, therefore, proceeds from the assumption that the position of persons with disabilities is socially conditioned, that is, that social barriers lead to their discrimination, due to unorganized activities of the society in removing obstacles and social constraints (Oliver, 1996). The social model sees disability, as a product of a social context and the environment in which a person is counting and its physical structure, object design, transport and the like (Pešić, 2006). The problem of a person with disabilities is located within an individual, that is, a person with disabilities due to their disability requiring medical intervention, in order to adapt to society. 
In addition to the medical model, institutional protection of people with disabilities is closely linked (Crisp, 2000). Terminological interpretations, which emphasize limitation, disturbance and incompetence, relationships between a person and the environment (Howard, 1998).

\section{AIM OF THIS PAPER}

The aim of the paper is to determine the differences in the perception of the accessibility of the environment between young people with disabilities and young people without disabilities.

\section{WORK METHODS}

\section{Sample of respondents}

The sample of respondents consisted of two subsamples. The first sub-sample consisted of young people with disabilities, chronological ages 18-35 years, both sexes, 50 of them. The second subunit consisted of young people without disabilities, chronological age 18-35 years, both sexes, 50 of them, selected by random selection method from the Tuzla Canton area.

\section{Method of conducting research}

The research was conducted over a period of two months during which field testing was carried out. Each respondent answered independently after previously receiving instructions from the interviewers. Respondents were asked to express their agreement or disagreement, or the degree of agreement or disagreement with the views expressed in the assertions. Young people with disabilities are interviewed individually. The time that was scheduled for the interview with each respondent is 1525 minutes. Young people without disabilities are interviewed in groups. The time required to complete the questionnaires provided by this study is 15 minutes. All respondents were familiar with the research goal and were informed about how to complete the questionnaire.

\section{Measuring instruments}

For the purposes of this research, a Questionnaire was used to examine the self-assessment of the adaptability of space and accessibility of the environment (Bratovčić \& Mehmedinović, 2015) and it examines the following problem areas: Accessibility of housing, Accessibility of public transport, Accessibility of the environment, Accessibility of cultural institutions, Accessibility of administrative institutions, Accessibility of health institutions, Accessibility of self-service, café Accessibility, restaurant Accessibility, school / faculty Accessibility. The respondents' task is to have a scale of 1 to 5 assessments in which the space is suitably adapted, i.e. an accessible environment, where 1 means that it is very poor, and 5 means that adaptability / accessibility is very good.

\section{Data processing methods}

The data obtained by the research were processed using the method of parametric and nonparametric statistics. Frequencies, percentages and measures of central tendency are calculated (arithmetic mean, standard deviation). To investigate the differences between the tested variables, p-values were used, and variance analysis was used to test the significance of the differences. The data is shown in the table. The data was processed in the statistical package SPSS 16 for Windows.

\section{RESULTS}

In order to examine the perception of environmental adaptation to persons with disabilities and to determine the differences in the perception of environmental adaptability by persons with disabilities and persons without disabilities, a questionnaire was applied with a set of questions related to the assessment of the adaptability of housing, public transport and the environment, cultural, administrative, health and educational institutions. Table 1 shows the average values of assessments given in self-assessment of space adaptability and accessibility of the environment by young people with disabilities and young people without disabilities. 
Table 1. Differences in accessibility of the environment between young people with disabilities and young people without disabilities

\begin{tabular}{|c|c|c|c|}
\hline \multirow{2}{*}{ Questions } & \multirow{2}{*}{$\begin{array}{l}\text { Control group } \\
\mu \pm \sigma\end{array}$} & \multirow{2}{*}{$\begin{array}{l}\text { Experimental group } \\
\mu \pm \sigma\end{array}$} & \multirow{2}{*}{$\mathbf{p}$} \\
\hline & & & \\
\hline \multicolumn{4}{|l|}{ Accessibility of housing } \\
\hline Kitchen & $4.74 \pm .53$ & $4.20 \pm 1.03$ & .00 \\
\hline Bedroom & $4.74 \pm .53$ & $4.26 \pm .94$ & .00 \\
\hline Toilet & $4.76 \pm .48$ & $4.24 \pm .96$ & .00 \\
\hline Living room & $4.76 \pm .48$ & $4.24 \pm .96$ & .00 \\
\hline Entrance & $4.66 \pm .75$ & $3.98 \pm 1.32$ & .00 \\
\hline \multicolumn{4}{|c|}{ Accessibility of public transport and environment } \\
\hline Accessibility of public transport & $4.04 \pm 1.47$ & $2.82 \pm 1.51$ & .00 \\
\hline Accessibility to the environment & $4.10 \pm 1.45$ & $3.00 \pm 1.41$ & .00 \\
\hline \multicolumn{4}{|c|}{ Accessibility of cultural institutions } \\
\hline Theatre & $4.44 \pm .95$ & $3.16 \pm 1.20$ & .00 \\
\hline Cinema & $4.50 \pm .76$ & $3.18 \pm 1.24$ & .00 \\
\hline Cultural Centre & $4.52 \pm .74$ & $3.12 \pm 1.19$ & .00 \\
\hline Library & $4.46 \pm .89$ & $3.18 \pm 1.22$ & .00 \\
\hline Accessibility of sports facilities & $4.54 \pm .73$ & $3.22 \pm 1.17$ & .00 \\
\hline \multicolumn{4}{|c|}{ Accessibility of administrative institutions } \\
\hline Administration & $4.42 \pm .95$ & $3.08 \pm 1.14$ & .00 \\
\hline Centre for Social Work & $4.38 \pm 1.05$ & $3.06 \pm 1.24$ & .00 \\
\hline Employment office & $4.38 \pm 1.05$ & $3.04 \pm 1.19$ & .00 \\
\hline \multicolumn{4}{|l|}{ Accessibility of health institutions } \\
\hline Health centre / clinic & $4.38 \pm 1.10$ & $3.00 \pm 1.25$ & .00 \\
\hline Hospital & $4.46 \pm .99$ & $3.12 \pm 1.22$ & .00 \\
\hline \multicolumn{4}{|l|}{ Accessibility of other objects } \\
\hline Accessibility of self-service & $4.74 \pm .56$ & $3.74 \pm 1.12$ & .00 \\
\hline café Accessibility & $4.68 \pm .62$ & $3.66 \pm 1.21$ & .00 \\
\hline restaurant Accessibility & $4.68 \pm .62$ & $3.66 \pm 1.17$ & .00 \\
\hline \multicolumn{4}{|l|}{ school / faculty Accessibility } \\
\hline Entrance & $4.28 \pm 1.16$ & $3.38 \pm 1.10$ & .00 \\
\hline Classroom & $4.20 \pm 1.25$ & $3.48 \pm 1.03$ & .00 \\
\hline Toilet & $4.18 \pm 1.27$ & $3.40 \pm 0.97$ & .00 \\
\hline Laboratory & $4.20 \pm 1.25$ & $3.40 \pm 0.99$ & .00 \\
\hline Library & $4.26 \pm 1.19$ & $3.44 \pm 1.03$ & .00 \\
\hline
\end{tabular}

Based on the data presented in Table 1, it can be seen that there is a statistically significant difference $(p<$ .05 ) in the average assessment of the adaptability of space and the accessibility of the environment between young people with disabilities and young people without disabilities. Adaptability of space and ac- cessibility of the environment is estimated on average by a higher rating in young people without disabilities, unlike in young people with disabilities. Young people with disabilities are the worst evaluators of the accessibility of public transport and the environment, and the best evaluators of accessibility of housing. 


\section{DISCUSSION}

People with disabilities have the option of choosing their place of residence, where and with whom they will live, on equal terms with others, and that they are not forced to live under a particular program, they have access to a number of support services in their homes, accommodation facilities and other support services in the local community, including personal assistance needed to support life and community involvement, and to prevent isolation or exclusion from the community. Services in the local community, equipment and facilities intended for the general population are available on an equal footing to persons with disabilities and are in line with their needs (Vučenović \& Mastikosa, 2011).

According to the report of the Ministry of Health of Serbia (2006), only $37 \%$ of young people are thinking about their health when choosing a diet. The regularity of hygienic habits (showering and tooth brushing) among youth in the Republic of Serbia declined in 2006 compared to 2000 and is less pronounced in the population of those living in poverty. There is still a small number of interventions and programs aimed at particularly vulnerable groups of young people. The percentage of those with some form of chronic illness is, as a rule, higher among poorer groups than among those who live with monthly incomes above the poverty line. This difference is particularly noticeable when chronic illnesses that lead to some form of long-term incapacity - disability (20\%) among people living in poverty and $(7 \%)$ among those living above the poverty line are observed. In one part of the youth population, who live with disabilities or have other developmental difficulties, there is an accumulation of unfavourable conditions in terms of additional activities of the poverty factor.

Young people with disabilities are better able to assess the ability to do things the way they want and when they want, compared to their parents, also a higher percentage of young people with disabilities $(67.5 \%)$ think they are capable of taking care of themselves (to make food, to maintain hygiene, to clean house, and clothing), from the parents of persons with disabilities. On the other hand, in the same research, it is stated that parents consider that young people with disabilities can decide on their movement where and when they want (with or without additional support or assistance), which disagrees with young people with disabilities (Mehmedinović \&
Bratovčić, 2015). According to the research "Comparative research on the quality of employment of people with disabilities", the results showed that, out of the total number of respondents, $92.2 \%$ answered the question that relates to the support of other persons in carrying out activities of everyday life. More than half of this number believes that they do not need any support from other people in performing these activities (63.3\%). Among respondents who stated that they need support in daily life activities, they mostly refer to performing administrative work, leaving the place of residence, doing housework, moving and transport (Ljubinković, 2009). The results of the survey show that people with disabilities usually need the following types of support: support in movement and transportation, support related to the procurement of household tasks, support for social contacts, support for the maintenance of personal hygiene, assistance in education, support for the performance of professional obligations, support for nutrition (Rajkov \& Ljubinković, 2001). Personal assistant support relates to support related to: personal care (hygiene, dressing, toilet needs and the like), grocery and meal preparation, home affairs - washing clothes, dishes, maintenance of home hygiene, home budget management, communication support, telephone use, medical services (e.g. drug delivery, catheterization, respiratory pumps), adapting the living space to the needs of service users, supporting the use of supplies, transfer support (bed - wheelchairs, carriages, etc.) (Dinkić \& Momčilović, 2005). Support for movement, transportation and more. The results of the research and analysis (ACED, 2014) show that the legislative framework in the areas of accessibility, education, health care, work and employment, social protection is largely aligned with the provisions of the UN Convention, but that there are problems in practice mostly due to the lack of proper the mechanisms necessary for their implementation, such as regulations, decisions, regulations or guidelines, or because they have not allocated funds in the budget for their implementation.

\section{CONCLUSION}

On the basis of the obtained research results that show that there is a statistically significant difference ( $p$ $<.05)$ in the average assessment of the adaptability of space and the accessibility of the environment to persons with disabilities between young people with disabilities and young people without disabilities. 
Adaptability of space and accessibility of the environment is estimated on average by a higher rating by young people without disabilities. Young people with disabilities are the worst evaluators of the accessibility of public transport and the environment, and the best evaluators of accessibility of housing. Appropriate support for children and young people with disabilities at all levels of education should be provided with the aim of achieving the highest quality of academic and personal skills necessary for independence and employment.

\section{REFERENCES}

Agency for Cooperation, Education and Development (ACED). (2014). Report on the Compliance of the Legislative and Institutional Framework in Bosnia and Herzegovina with the UN Convention on the Rights of Persons / Persons with Disabilities with Recommendations for Harmonization. European Union Program for Bosnia and Herzegovina. Banja Luka: UNIGRAF d.o.o.

Bratovčić, V., \& Galijašević, Z. (2015). Strengthening capacities for the independent life of persons with disabilities in $\mathrm{BiH}$ - peer support - Manual for trainers of young people with disabilities. Tuzla:Information Center "Lotos".

Bratovčić, V., \& Mehmedinović, S. (2015). The path to independence. Report on research on the attitudes of young people with disabilities and their families about the rights and abilities of persons with disabilities in the Tuzla Canton. Project: Strengthening capacities for the independent life of persons with disabilities in Bih. Tuzla: Information Centre for People with Disabilities: Lotos.

Crisp, R. (2000). Aqualitative Study of the Perceptions of Individuals with Disabilities Conceming Health and Rehabilitation Professionals. Disability \& Society. 15 (2): 355- 367.

Dinkić, M., \& Momčilović, J. (2005). Cost of Independence: Analysis of the justification of investment in organizing the service of personal assistants to help people with disabilities in Serbia. \{on line\} Belgrade. Retrieved 6.10.2015, from http://www.cilsrbija.org/
Howard, M. (1998). Active policies: Helping disabled people to participate in the labour market. New Economy: 5 (4): 219-224.

Husić-Đuzić, I. (2016). Evaluation of the success in the life skills of young persons with disabilities, Master thesis. Faculty of Education and Rehabilitation, University of Tuzla.

Erikson, E.H. (2008). Identity and Life Cycles. Belgrade: Institute for Textbooks.

European Strategy for People with Disabilities 2010-2020. \{on line\} Retrieved 14/02/2016, from the website http://www. cerebralnaparaliza.rs/za-organizacije-i-clanove/232-evropska-strategija-za-osobe-sa-invaliditetom-2010-2020.

Ljubinković, B. (2009). Comparative research on the quality of employment of people with disabilities. Belgrade: Centre for Independent Living of the Disabled of Serbia.

Matković, A., \& Načinović, L. (2015). Employment of people with disabilities. mployee. Handbook, Republic of Croatia.

Oliver, M. (1996). Understanding Disability from theory to practice. London.

Omolayo, B. (2009). Effects of leadership styles on job related tension and psychological sense of community in work organization: case study of four organization in Lagos State. Nigeria: Bangladesh.

Pešić, V. (2006). European Union and people with disabilities. People's Office of the President of the Republic. Friedrich E. S., Beograd, 15-16.

Petition to support people with disabilities (2015). \{on line\} Available at: http://www.onlinepeticija.com/peticija_za podrku_osobama_s_invaliditetom.

Rajkov, G., \& Ljubinković, B. (2001). "Serving personal assistants as a social service for people with disabilities". Case study. Belgrade.

Seligman, M. (2007). An optimistic child. Zagreb: IEP d.o.o.

Strnad, M., \& Benjak, T. (2010). International Classification of Functioning, Disability and Health. Zagreb: Medical books.

Trombly, C. (1995). Occupational therapy for Physical Dysfunction. Baltimore: Maryland.

Vučenović, D., \& Mastikosa, O. (2011). Independent life of people with disabilities. Banja Luka. [cited] available from http://www.ho-partner.rs.sr/brosure/samostala_zivot. 